\title{
Study of awareness, perception about strabismus and social impact of strabismus in adults attending tertiary care centre
}

\author{
Subramanya Kota ${ }^{1, *}$, Vinuta Mohan Kulkarni

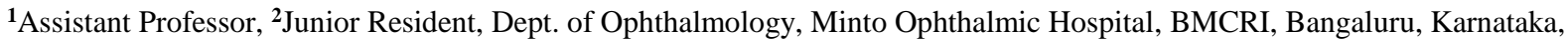 \\ India
}

*Corresponding Author:

Email: subramanyakota@gmail.com

\begin{abstract}
Aim: Strabismus is the common condition seen in children and adults in our society. Strabismus has variety of psychosocial impact that can affect the quality of life of the patients. Proper education and awareness regarding the condition can help to rule out the myths associated with strabismus and also building up the personality of the patients. This study was done to know the level of awareness, knowledge about the strabismus in our population and the social impact of strabismus in patients life.

Material and Methods: Cross sectional study conducted on 196 patients with strabismus attending outpatient department of Minto Ophthalmic Hospital, regional institute of ophthalmology were included in the study. After taking informed consent, face to face interview conducted asking questions from structured questionnaire prepared. Data collected and analysed with descriptive statistics.

Results: Out of 196 patients included in the patients, 128 were males and 68 females. About $9.6 \%$ of patients, were unaware of the condition of strabismus, $56.3 \%$ were unaware that squint can cause visual disturbance, $63 \%$ were unaware of that strabismus can be treated, $37 \%$ of people felt like surgery is the only mode of treatment for strabismus. $60 \%$ of the study population expressed that they were rejected for being married due to strabismus because of cosmetic affect, $42.4 \%$ felt like squint can hinder the social leadership, $36 \%$ had difficulty in getting job, $28 \%$ of the patients expressed being criticized by their friends that lowered their confidence, $75 \%$ of the patients felt that they look ugly because of strabismus.

Conclusion: Strabismus apart from causing ocular problems, is associated with many psycho-social impact on life of patients. There is lack of awareness regarding the strabismus in our population. Attitude and perception of society towards patients with strabismus will affect the overall confidence, personality of the patients and hence affect quality of life. Hence awareness about the condition, treatment availability is necessary to build up the overall personality of the patients with strabismus, to have better life.
\end{abstract}

Keywords: Awareness about strabismus, Social impact.

\section{Introduction}

Strabismus is the condition in which there is misalignment of visual axes. People with manifest strabismus face many psychosocial problems in their life. This is seen in all the ages from children to middle aged patients. In early childhood, patients with strabismus, apart from suffering problems associated with vision, depth perception, they also face various problems such as rejection from friends, inter personal relationship, participating in sports, finding playmates in school that can affect the childrens personality development. ${ }^{1,2}$ Although in some of the patients, strabismus may be due to delayed development, most of the patients with strabismus are regarded as having low intelligence and less competent as compared to children without strabismus. ${ }^{3}$ Apart from these, as they grow up to adult social challenges increase and pose new problems. Difficulty in making relationships, marriage, ${ }^{5}$ job employment, ${ }^{4}$ lack of confidence, considered as unlucky by the family are the various problems faced by adults with strabismus. Our study intended to analyse the various social problems, perception and awareness about the strabismus in patients with strabismus in the tertiary care center.

\section{Material and Methods}

This is the prospective study done of patients attending out patient department of Minto Ophthalmic Hospital, regional institute of ophthalmology, Bangalore, presenting with complaint of deviation of eyes. A total of patients in the age group of 20-30 years were include in our study from March 2017 to March 2018. Informed consent taken for the patients included in the study. Structured questionnaire containing 10 questions prepared based on the review of various literature and socio-economic aspects of our society. Face to face interviews conducted and the answers for the questions taken. Data collected and analysed with descriptive statistics.

\section{Results}

Out of 196 patients included in the patients, 128 were males and 68 females (Table 1). About $39 \%$ had education upto primary education (Class 7). About 9.6 $\%$ of patients, were unaware of the condition of strabismus. $63 \%$ of this total study people are unaware of that strabismus can be treated. $56.3 \%$ of the study group unaware that squint can cause visual disturbance. $37 \%$ of people felt like surgery is the only mode of treatment for strabismus (Table 2). 60\% of 
the study population expressed that they were rejected for being married due to strabismus because of cosmetic affect. $42.4 \%$ of the study group felt like squint can hinder the social leadership. $36 \%$ of the study group had difficulty in getting job due to strabismus. $28 \%$ of the patients expressed being criticized by their friends that lowered their confidence. $75 \%$ of the patients felt that they look ugly because of strabismus. (Table 3 )

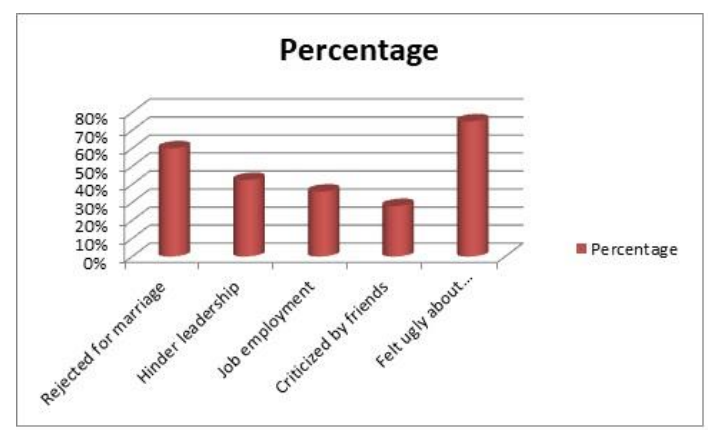

Fig. 1

Table 1: Sex Distribution

\begin{tabular}{|l|c|c|}
\hline \multicolumn{1}{|c|}{ Sex } & Number & Percentage \\
\hline Males & 128 & $65 \%$ \\
\hline Females & 68 & $35 \%$ \\
\hline
\end{tabular}

Table 2: Awareness about strabismus

\begin{tabular}{|l|c|}
\hline \multicolumn{1}{|c|}{ Awareness } & Percentage \\
\hline Unaware of condition & $9.6 \%$ \\
\hline $\begin{array}{l}\text { Unaware about the } \\
\text { treatment }\end{array}$ & $63 \%$ \\
\hline $\begin{array}{l}\text { Unaware that it can cause } \\
\text { Visual disturbance }\end{array}$ & $56.3 \%$ \\
\hline $\begin{array}{l}\text { Thought surgery is the only } \\
\text { treatment }\end{array}$ & $37 \%$ \\
\hline
\end{tabular}

Table 3: Social impact of strabismus

\begin{tabular}{|l|c|}
\hline \multicolumn{1}{|c|}{ Social problem } & Percentage \\
\hline Rejected for marriage & $60 \%$ \\
\hline Hinder leadership & $42.4 \%$ \\
\hline Job employment & $36 \%$ \\
\hline Criticized by friends & $28 \%$ \\
\hline Felt ugly about themselves & $75 \%$ \\
\hline
\end{tabular}

\section{Discussion}

Strabismus is the misalignment of the visual axes, seen as deviation of eye, which may be caused by abnormalities in binocular vision or by anomalies of neuromuscular control of ocular motility. It may be congenital or acquired. Deviation of eyes which is cosmetically less acceptable compared to normal individuals can cause various social problems in patients with strabismus.

Many studies have been done on social and psychological impact of strabismus. ${ }^{1,2,4-6}$ Most of our patients had low educational status, 39\% and were unaware that strabismus can be treated,63\%. This made them to delay to seek health professional help. This shows that awareness regarding strabismus treatment is much needed in our society. There considerable gap between the time patients realise that they have strabismus and time they come to health professionals for treatment. This is due to various cultural factors involved in our society, myths related to the cause of strabismus. Similar results are seen in various studies done in United kingdom and France. ${ }^{7,8}$ In one of the Indian study, they found that lack of awareness about the treatment availability as the main cause of delayed presentation. ${ }^{9}$

Various studies are done to show the social difficulties, patients with strabismus face in their lifetime. .,5,10,11 Our study showed that strabismus patients face difficulty in getting job (36\%), finding partners in life $(60 \%)$ that will lower their confidence and hence social and mental well being. In similar study it was found that patients with strabismus were judged significantly negative as compared to individuals without strabismus. ${ }^{3}$ Around $75 \%$ of patients with strabismus had opinion that they look ugly because of their strabismus and hence find difficulty in maintaining healthy inter-personal relationships due to inferior complexity. This is important aspect as such patients may land up in depression over the period.

Proper counselling is required in such patients to boost up their confidence level and timely surgery can treat the condition giving them better life. In one of the study conducted by Archer et al, ${ }^{12}$ they found that there is significant psychosocial benefit in patients with strabismus after surgical correction. By creating awareness about the condition and treatment availability, we can positively change the attitude of the patients with strabismus thus improving the social well-being of them. Timely treatment, proper counselling of patients with strabismus is thus necessary to give them better life. Further studies are required in large scale to understand the various cultural, social aspects associated with the condition.

\section{Conclusion}

Strabismus is a known to cause significant negative psychosocial impact in patients with strabismus. There is need for the awareness about the condition and treatment available to reduce the delay in treatment. Awareness, proper counselling is thus necessary to improve the social and psychological status of the patients with strabismus.

Funding: No funding sources. Conflict of interest: None declared. 


\section{References}

1. Satterfield D, Keltner JL, Morrison TL. Psychosocial aspects of strabismus study. Arch Ophthalmol 1993;111:1100-05.

2. Robaei D, Rose KA, Kifley A, Cosstick M, Ip JM, Mitchell P. Factors associated with childhood strabismus: Findings from a population-based study. Ophthalmol 2006;113:1146-53.

3. Olitsky SE, Sudesh S, Graziano A, Hamblen J, Brooks $\mathrm{SE}$, Shaha SH. The negative psychosocial impact of strabismus in adults. J AAPOS 1999;3:209-11.

4. Coats D, Paysse E, Towler A et al. Impact of large angle horizontal strabismus on ability to obtain employment. Ophthalmol 2000;107:402-05.

5. Mojon-Azzi SM, Potnik W, Mojon DS. Opinions of dating agents about strabismic subjects' ability to find a partner. Br J Ophthalmol 2008;92:765-69.

6. 6.Menon V, Saha J, Tandon R, Mehta M, Khokhar S. Study of the psychosocial aspects of strabismus. $J$ Pediatr Ophthalmol Strabismus 2002;39:203-08.

7. Coats DK, Stager DR Sr., Beauchamp GR, Stager DR Jr., Mazow ML, Paysse EA, et al. Reasons for delay of surgical intervention in adult strabismus. Arch Ophthalmol 2005;123:497-99.

8. Spielmann AC, Spielman A. Oculomotor surgery in adult patients: Why is it so frequently rejected? In:
Spiritus M, editor. Transactions of the 25th Meeting European Strabismological Association. Lisse,

Netherlands: Aeolus Press Science Publisher; 2000. p. 186-91

9. Sathyan S, Jose J. Barriers responsible for delay in surgical correction of strabismus: A study among adults undergoing strabismus surgery at a tertiary care center in Kerala. Kerala J Ophthalmol 2017;29:102-07.

10. Kothari, M., Balankhe, S., Gawade, R., \& Toshnival, S. Comparison of psychosocial and emotional consequences of childhood strabismus on the families from rural and urban India. Indian J Ophthalmol 2009;57(4):285-88.

11. Hatt SR, Leske DA, Kirgis PA, Bradley EA, Holmes JM. The effects of strabismus on quality of life in adults. Am J Ophthalmol 2007;144:643-47.

12. Archer SM, Musch DC, Wren PA, Guire KE, Del Monte MA. Social and emotional impact of strabismus surgery on quality of life in children. $J A A P O S$ 2005;9:148-51.

How to cite the article: Kota S., Kulkarni V. Study of awareness, perception about strabismus and social impact of strabismus in adults attending tertiary care centre. Int $J$ Ocul Oncol Oculoplasty 2018;4(3):124-126. 